\title{
Burnout: exploring the differences between U.S. and international medical graduates
}

Joan E. St. Onge ${ }^{1 *} \mathbb{D}$, Heidi Allespach², Yvonne Diaz ${ }^{1,3}$, Alexandria Poitier ${ }^{4}$, Leonardo Tamariz ${ }^{1}$, Charles Paidas $^{5,6}$ and Ana Palacio ${ }^{7}$

\begin{abstract}
Background: International medical graduates (IMGs) have less burnout than U. S. medical school graduates (USMGs) during residency training. This study evaluates possible correlates of differences in burnout rates between USMGs and IMGs.

Methods: We surveyed 375 first-year residents at orientation in June/July 2017. We assessed burnout using the Copenhagen Burnout Inventory (CBI) and used validated scales to measure stress, quality of life (QoL), mastery, and spirituality. We collected data on gender, place of graduation, language fluency, and specialty. We compared CBI scores between USMGs and IMGs, performed a multivariate linear regression analysis of relationships between covariates and CBI subscales, and logistic regression analysis for our categorical definition of burnout.

Results: Two hundred twenty-two residents responded for a response rate of 59\%. Personal, work or patient- related burnout was common among residents, particularly among USMGs. The most common form of burnout was workrelated. Forty nine percent of USMGs have work burnout compared to $26 \%$ of IMGs $(p<0.01)$. In multivariate analysis, being an IMG reduced odds of work-related and of total burnout by 50\% (OR 0.5 C.I 0.25-0.99). Perceived mastery was associated with reductions in all subscales of burnout $(p<0.05)$. Stress and low QoL related to personal and work burnout scores $(p<0.01)$.

Conclusion: Work-related burnout is more common among USMGs than in IMGs. Although mastery, QoL and stress were correlates of burnout among all residents, these factors did not explain the difference. Future studies should evaluate the role of medical school structure and curriculum on differences in burnout rates between the two groups.
\end{abstract}

Keywords: Physician burnout, Well-being, Curriculum, Medical education

\section{Background}

Burnout, a triad of emotional exhaustion, cynicism, and reduced personal accomplishment [1] affects up to $74 \%$ of physicians [2]. Medical students, residents and practicing physicians have higher rates of burnout than aged

\footnotetext{
*Correspondence: jestonge@med.miami.edu

${ }^{1}$ Department of Medicine, University of Miami Leonard M. Miller School of Medicine, 1600 NW 10th Avenue, Suite 1124, Miami, Florida 33136, USA Full list of author information is available at the end of the article
}

matched controls [3]. Burnout has been associated with a number of personal and professional consequences which negatively affect physician quality of life, productivity and the quality of care patients receive [4-12].

The literature has illuminated several individual-level drivers of burnout. For example, residents with greater perceived stress are more likely to report symptoms of burnout [13-16] and medical students and physicians with a lower sense of control over their lives and schedules exhibit a higher incidence of burnout [14, 17-19]. 
Protective factors have also been identified, and these include work-life balance [20], aerobic exercise [21], and spiritual involvement and beliefs [22-25]. These protective factors are enhanced by the use of effective coping strategies, as well as by perceptions of personal accomplishment [26, 27].

Two large cohort studies found that international medical graduates (IMGs) have lower rates of burnout than graduates of US medical schools (USMGs), and IMGs report higher ratings of quality of life (QoL), self-esteem and person growth scores [26-28]. However, these studies had limited data on personal attributes which could explain the variance between these groups. It has been demonstrated that learning styles are more self-directed in IMGs, which may be a protective factor [29]. Lower levels of debt in IMGs may also contribute to less burnout among IMGs [26]. Understanding differences and similarities between USMGs and IMGs may help identify and mitigate factors implicated in the development of burnout. The aim of this study was to evaluate both the prevalence of burnout, and the contribution of personal attributes to burnout among USMGs and IMGs at the onset of their first year of post-graduate training.

\section{Methods}

The University of Miami Miller School of Medicine Institutional Review Board approved this research protocol. We included all incoming interns training in 21 specialties at University of Miami/Jackson Memorial Hospital (UM/JMH) and the University of South Florida Morsani College of Medicine (USF).

We distributed the 51-item survey during orientation between June 20 and July 1, 2017. The survey assessed burnout and covariates, including perceived stress, mastery, depression, spirituality, QoL and current use of wellness techniques.

We used the Copenhagen Burnout Inventory (CBI) to measure burnout due to its ability to capture revealing factors specific to burnout. The CBI, was developed by Kristensen and colleagues for use in the PUMA Study (Danish acronym for Project on Burnout, Motivation and Job Satisfaction) to investigate increasing rates of long term sick leave and early retirement in union workers [30]. They found that scores on the three measures of the CBI have been shown to predict sleep problems, use of pain killers, absence from work and intention to quit [30]. In addition, the CBI may be preferable for an international cohort, as the often-used Maslach Burnout Inventory was found to be problematic for Danish workers in the PUMA plot study, who found some of the questions were not applicable to their world view and belief system [30]. In spite of a recent uptake on the use of the CBI for the evaluation of burnout, very few studies have utilized it to study burnout in residents [31,32] and none have used CBI to compare burnout between USMGs and IMGs.

The CBI is a 19-item questionnaire with three subscales that measure personal burnout, work-related burnout and client-related burnout. In our survey, we used the term, "patients" instead of "clients." The three sub-scales of CBI use a 5 -point Likert scale associated to values ranging from 0 to 100 . The results of the three subscales are totaled separately and averaged to determine a total burnout score. Higher scores correlate to higher levels of burnout. All three scales have very high internal reliability, and small non-response rates. In the PUMA study, the scales differentiated well between occupational groups in the human service sector, and identified the expected pattern of correlations with other measures of fatigue and psychological well-being [30]. For categorical analysis, we used the average burnout scores reported in the PUMA study for chief physicians as a cut point for burnout [30].

The Pearlin Mastery Scale, a validated 7-item measures the extent to which "an individual feels their life chances are under their own control in contrast to being fatalistically ruled." Higher scores indicate higher levels of mastery [33, 34]. It is important to note that "mastery" in this context does not refer to the competency to perform, but to perception of control over one's life.

The Perceived Stress Scale 4, a validated four-item scale measures the degree to which one views life situations as stressful. Higher scores correlate to more perceived stress [35].

The Patient Health Questionnaire-2 (PHQ-2) is a 2-item screen for depression. Higher scores indicate a higher probability of a major depressive disorder $[36,37]$.

We measured spirituality using a one-question True/ False item: "My spiritual beliefs are very important in helping me cope with stressors." [38]

To measure QoL, we used a one-item assessment "How satisfied are you with your quality of life at this time?” [39]

We assessed engagement in stress management strategies which have been found to be effective in the literature: cognitive-restructuring, mindfulness, diaphragmatic breathing, brief relaxation and daily selfcare [40].

\section{Statistical analysis}

We evaluated the distribution of the continuous variables using measures of central tendency and skewedness. We compared baseline characteristics by place of graduation (USMGs and IMGs) using chi square and t-test, and used $\mathrm{t}$-test to compare average scores of personal, work and client-related burnout between USMGs and IMGs. 
We used chi square to compare the proportion of USMGs and IMGs with personal, work, patient burnout scores higher than the averages reported in the PUMA study (categorical burnout definition). We utilized a similar strategy to compare the proportion who had scores higher than the PUMA study averages in all three subscales combined.

We conducted a multivariate linear regression analysis of relationships between all covariates and each of the three continuous subscales. We utilized logistic regression analysis for the categorical definition of burnout. The categorical outcome was having scores higher than the average reported in PUMA across the three subscales simultaneously. We report the odds ratio and corresponding 95\% confidence interval (CI) for all models. Models included all covariates described above.

The fitness of the data was assessed using the deviance ratio. Analyses were performed using STATA version (College Station, Texas), and all significance tests were two-tailed.

\section{Results}

Of 375 eligible residents (200 UM/JMH and 175 at USF) at both institutions, 222 completed the questionnaire for a response rate of $59 \%$. Baseline characteristics of USMGs and IMGs were similar. (Table 1). Both groups had similar high QoL and mastery scores, but also similar moderate to high-perceived stress. IMGs were significantly more likely to report their spiritual beliefs helped them cope with stress and were more likely to report a primary language other than English.
The mean $+/-$ SD for the three burnout subscales were $30.07+/-13.6$ for personal burnout, $38+/-13$ for work burnout and $18.8+/-14.6$ for patient-related burnout.

We found the distribution of burnout scores differed according to place of graduation. (Fig. 1).

The largest difference between USMGs and IMGs was in work-related burnout $(39.9+/-12.9$ versus 30.9 $+/-10.5$ respectively). However, personal burnout and patient-related burnout scores were also approximately 5 percentage points lower among IMGs. The creators of the scale described a $5 \%$ difference as the cut point for a significant difference in burnout [30].

\section{Burnout as a categorical variable}

Among USMGs, one in two residents scored higher than the PUMA average for work burnout and one in three residents scored higher for personal or patient burnout. In contrast, among IMGs, one in four residents scored higher than PUMA averages for personal or work burnout and one in five for patient burnout. Interestingly, we found that $12 \%$ of USMG graduates had higher scores than PUMA for the three subscales simultaneously, compared to only $5 \%$ of IMGs. (Table 2 ).

\section{Correlates of personal, work and patient burnout}

Our linear regression models found that associations between individual-level covariates and burnout varied across each of the three subscales: We found that higher mastery, or having more control over life's events, lower perceived stress and higher QoL were associated with less personal and work-related burnout $(p<0.05)$. The strongest correlate of work burnout

Table 1 Baseline characteristics

\begin{tabular}{|c|c|c|c|c|}
\hline Characteristic & Overall & $\begin{array}{l}\text { Graduate outside of } \\
\text { the US }\end{array}$ & Graduated in the US & $p$-value \\
\hline Number & 222 & 43 & 179 & \\
\hline Female, $\%$ & 49 & 44 & 49 & 0.60 \\
\hline Non-surgical program, \% & 65 & 63 & 64 & 0.88 \\
\hline English is the primary language, \% & 65 & 19 & 77 & $<0.01$ \\
\hline Mastery score, mean +/-SD & $23.7+/-2.38$ & $23.6+/-2.4$ & $24.0+/-2.0$ & 0.38 \\
\hline Stress score, mean +/-SD & $8.6+/-1.6$ & $8.7+/-1.8$ & $8.5+/-1.6$ & 0.38 \\
\hline Quality of life, mean +/-SD & $5.32+/-0.86$ & $5.45+/-0.88$ & $5.28+/-0.86$ & 0.27 \\
\hline Spiritual belief, \% & 58 & 86 & 51 & $<0.01$ \\
\hline Depression, \% & 2 & 2 & 1 & 0.52 \\
\hline Any wellness technique, \% & 68 & 79 & 66 & 0.09 \\
\hline Cognitive restructuring, \% & 45 & 51 & 43 & 0.33 \\
\hline Mindfulness, \% & 38 & 37 & 38 & 0.92 \\
\hline Diaphragmatic breathing, \% & 21 & 16 & 22 & 0.38 \\
\hline Brief relaxation imagery, \% & 26 & 33 & 19 & 0.06 \\
\hline Cognitive restructuring, mean $+/ S D$ & $1.8+/-0.94$ & $1.37+/-1.09$ & $1.22+/-1.16$ & 0.46 \\
\hline
\end{tabular}




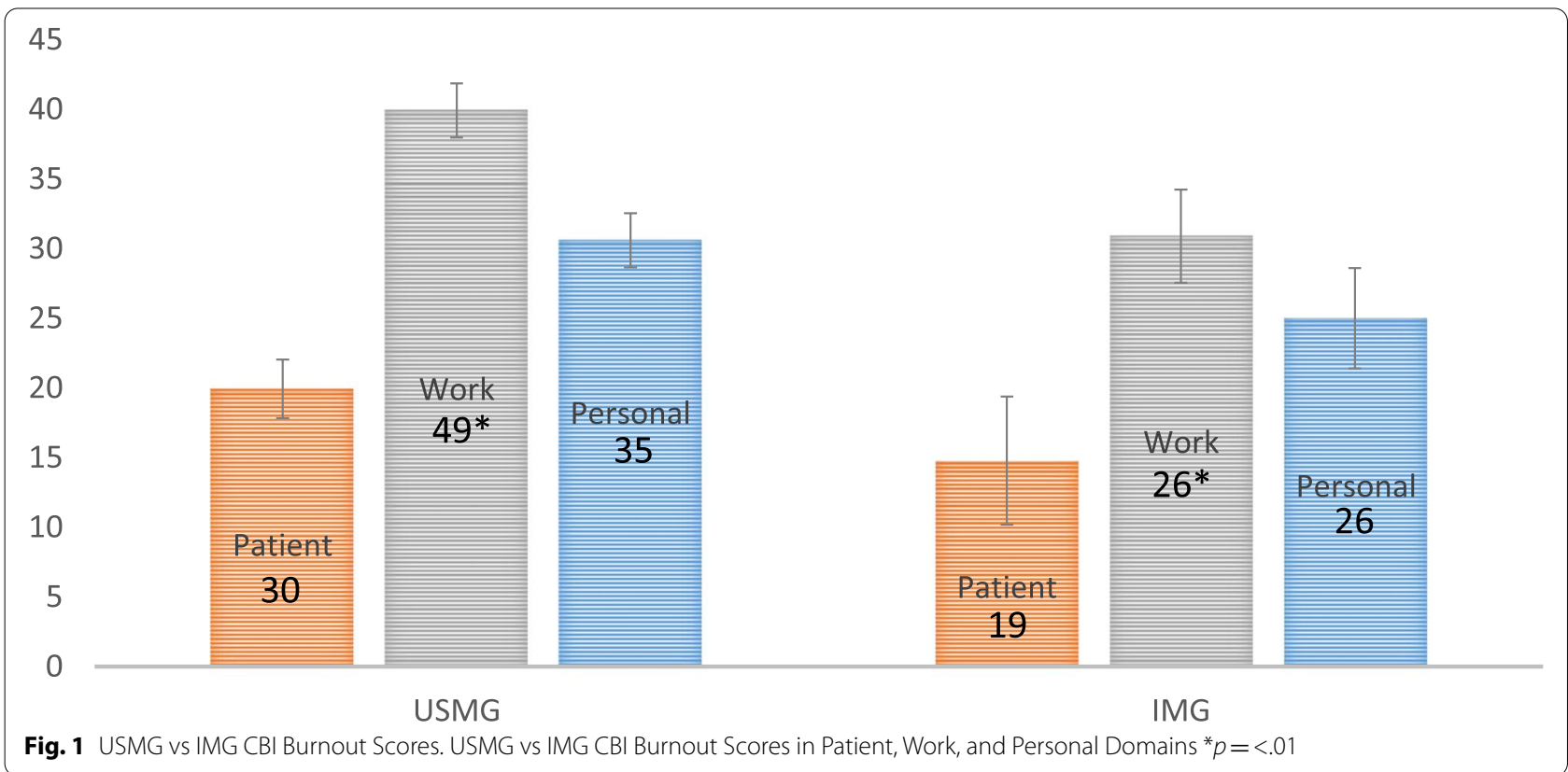

Table 2 Prevalence of Burnout as categorical variable by place of graduation

\begin{tabular}{|c|c|c|c|c|}
\hline & Entire group $(n=222)$ & $\begin{array}{l}\text { US graduates } \\
(n=179)\end{array}$ & $\begin{array}{l}\text { Foreign graduates } \\
(n=43)\end{array}$ & $p$ value \\
\hline Personal burnout,\% & 34 & 35 & 26 & 0.23 \\
\hline Work burnout, $\%$ & 44 & 49 & 26 & $<0.01$ \\
\hline Patient burnout, $\%$ & 27 & 30 & 19 & 0.11 \\
\hline Burnout in 3 components, $\%$ & 11 & 12 & 5 & 0.04 \\
\hline
\end{tabular}

was place of medical school graduation. International medical school graduation was associated with a reduction of almost 10 points in the work burnout score (C.I. $-15.05487-4.559158)$. Being female reduced the patientrelated burnout score by 4.5 points (C.I. -8.49657$.4862486)$ and each point increase in mastery reduced the patient burnout by 1.3 points (C.I. -2.135038.425182). Specialty, use of wellness techniques, and spirituality did not correlate with any burnout score. (Table 3).

\section{Correlates of combined burnout in all three subscales}

The logistic regression model found that IMGs $(p=0.04)$ and those with higher perception of mastery $(p<0.01)$ were significantly less likely to be burned out on the three burnout subscales simultaneously. Residents who indicated English as their primary language were almost twice as likely to report burnout compared to residents who indicated another primary language $(p=0.02)$ when adjusting for all other variables. (Table 4 ).

\section{Discussion}

Our study found higher prevalence of burnout among USMGs than in IMGs, consistent with previous research $[19,26,27]$. Importantly, our study contributes information on burnout correlates that has been lacking. We found that work-related burnout drives the difference between USMG and IMGs at the start of residency. However, the personal factors we evaluated did not explain the burnout difference. Perceived mastery, stress and QoL correlated with burnout among all residents.

Prior studies reported that English-speaking residents and those raised in the US or Canada were more likely to have higher rates of emotional exhaustion and depersonalization [41]. Low QoL has been correlated with symptoms of burnout [26]. However, studies evaluating other factors which account for the differences in burnout between USMGs and IMGs are limited. Increased resilience by virtue of successfully integrating into a US residency program may lead to a greater sense of mastery or lower perceived stress in IMGs when compared to USMGs. In our study, we did not see a difference in 
Table 3 Beta-coefficients for correlates of three burnout subscales

\begin{tabular}{|c|c|c|c|}
\hline Correlates & Personal burnout & Work burnout & Patient burnout \\
\hline UM/JMH vs USF & -.56 & .89 & -1.39 \\
\hline Women vs men & 1.45 & .35 & $-4.49^{3}$ \\
\hline Did not graduate in US & -3.64 & $-9.80^{1}$ & -2.67 \\
\hline Non-surgical vs surgical & -2.78 & -2.21 & 1.22 \\
\hline Fluent in English & 4.20 & -3.24 & 3.87 \\
\hline Mastery & $-1.20^{1}$ & $-1.24^{1}$ & $-1.28^{2}$ \\
\hline Stress & $1.41^{2}$ & $1.05^{3}$ & .90 \\
\hline Total wellness techniques & 1.05 & .72 & -.65 \\
\hline Depression & .69 & -6.30 & .99 \\
\hline Quality of life & $-3.33^{1}$ & $-3.65^{1}$ & -2.02 \\
\hline Spiritual & -.77 & -1.87885 & -1.65 \\
\hline
\end{tabular}

${ }^{1} p_{<0.001}$

$2 p<0.01$

$3 p<0.05$

Table 4 Multivariate predictors of having burnout in 3 subscales

\begin{tabular}{lll}
\hline Predictor & OR $(\mathbf{9 5} \% \mathbf{C l})$ & $\boldsymbol{p}$-value \\
\hline UM/JMH vs USF & $1.15(0.66-1.98)$ & 0.60 \\
Women vs men & $1.30(0.77-2.19)$ & 0.32 \\
Non-surgical vs surgical & $0.93(0.53-1.61)$ & 0.80 \\
Did not graduate in US & $0.50(0.25-0.99)$ & $\mathbf{0 . 0 4}$ \\
Mastery & $0.80(0.71-0.90)$ & $<\mathbf{0 . 0 1}$ \\
Stress & $1.12(0.96-1.32)$ & 0.13 \\
Fluent in English & $1.84(1.07-3.16)$ & $\mathbf{0 . 0 2}$ \\
Spiritual & $0.55(0.23-1.31)$ & 0.18 \\
Quality of life & $0.71(0.41-10)$ & 0.11 \\
Total wellness techniques & $0.96(0.68-1.35)$ & 0.83 \\
Depression & $0.41(0.06-2.5)$ & 0.37 \\
\hline
\end{tabular}

these covariates between these two groups. This is consistent with a 2009 study of internal medicine residents that showed no difference in perceived stress between IMGs and USMG during their residency [28]. Our study found that IMGs relied more on spirituality to cope with stress. While research has shown spirituality to have a protective effect against burnout in other groups [22-24, 42] spirituality was not a significant predictor of burnout in our study. A different prevalence of depression may also be a factor; however, in our cohort, the rate was low in both groups. The relationship between depression and burnout remains unclear [43].

The lack of differences in personal attributes between USMGs and IMGs suggests that aspects of the medical school experience may play a predominant role in burnout development. At the start of medical school, US medical students have shown lower rates of burnout and depression and higher QoL than aged-matched controls, indicating that burnout develops during medical school [44]. Therefore, differences in medical school curricula and experiences between USMGs and IMGs may help explain the difference in burnout. International medical graduates typically enter school immediately after high school, and complete 2-3 years of preclinical study followed by 3-4years of clinical study leading to a shorter premedical period and earlier clinical exposure [45]. Chen theorized that the perception that the United States Medical Licensing Exam (USMLE) Step 1 scores dictate a student's "worthiness" for higher achievement has contributed to increasing burnout in physicians and physicians-in-training [46]. While Step 1 scores may affect the future career of IMGs, these physicians usually take the test after medical school graduation. The recent decision by the National Board of Medical Examiners to change the USMLE Step 1 Exam to pass/fail grading [47] may help to mitigate this concern and elucidate the contribution of this high stakes exam to burnout.

It is important to note that higher perceived mastery, or a greater perception of having control over life's events, was associated with lower burnout scores in both cohorts. In addition, our finding that stress and QoL correlate to personal burnout suggests that contextual factors in the lives of USMGs and IMGs during medical school play a role in their coping abilities. Future studies should evaluate predictors of stress, QoL and perceived mastery among medical students. Our study had several limitations. The cross-sectional nature of our study prevented us from evaluating causality. While we used many validated scales, two of our measures were adapted to our cohort. We used a single item to measure QoL, which may not accurately 
reflect the QoL of our residents and only one question to ascertain the role of spiritual beliefs in coping with stress. To maintain anonymity of residents, we limited the specialty choice to "surgical" and "non-surgical" which did not allow us to analyze whether a specific specialty choice is a factor in burnout in our cohort. Residents reported their practice of wellness techniques, but we did not ascertain the quality or fidelity of their practice. The amount of debt incurred has been found to affect burnout rates in residents [26], but we did not measure debt in our study. We only included first year residents limiting our sample size and our ability to compare burnout and its predictors at different levels of training. In addition, comparing intern's responses with more senior residents or fellows would have further elucidated the relationship between selfperceived mastery (control over the events in one's life) and burnout. Importantly, it is possible that response bias contributed to the results of the study. IMGs may have felt pressure to answer the survey in what they perceived a more favorable manner than the USMGs. While the results of three of the subscales of the CBI found no statistical difference between USMGs and IMGs, response bias limits the interpretation of the overall results, and reinforces the need for study in more senior residents and fellows. Finally, the lack of direct measurements of health such as detailed medical histories or sleep assessments limit the clinical relevance of these findings.

The strengths of our study included its cohort: a diverse, multispecialty sample of residents from two institutions at the onset of training. Our evaluation of the role of mastery, perceived stress, QoL, spirituality and the practice of wellness techniques on burnout contributes to the literature that examines burnout rates in USMGs vs IMGs. Our findings have important implications regarding future directions of inquiry.

Finally, an additional strength is the utilization of the CBI. This scale provides a measurement of burnout that allows us to recognize the different burden of burnout in the personal, work and patient-related domains. In the PUMA study, results of the CBI in health-related workers correlated with outcomes such as a job satisfaction, sick days, sleep problems, and intention to quit work [30], increasing its relevance for evaluation of burnout in postgraduate learners, indicating clinical relevance of these findings. However, future studies using the CBI and other health assessments in USMGs and IMGs during training and beyond are needed to ascertain the true predictive clinical value of the results. The CBI's use and validity in studying an international cohort are important as we look beyond personal characteristics to study the institutional correlates of burnout.

\section{Conclusion}

At the onset of post-graduate training USMGs have a higher prevalence of work-related burnout than IMGs, a difference not explained by personal attributes. However, the use of the CBI identified that work-related burnout appeared to drive the difference between USMG and IMGs at the start of residency. Perceived control over one's life, stress and QoL correlated with burnout among all residents. IMGs relied more on spirituality to cope with stress, but spirituality was not a significant predictor of burnout in multivariate analysis.

Further research should evaluate the role of medical education structure, curriculum and environmental factors on burnout and impact of interventions that improve mastery and reduce stress in our learners. Continuing study on the differences between international and US medical education and effects on burnout and other health issues is an important component of future study.

\section{Abbreviations \\ CBI: Copenhagen Burnout Inventory; Cl: Confidence Interval; IMG: Interna- tional medical graduate; PHQ2: Patient Health Questionnaire 2; PUMA: Danish acronym, translated in English to "Project on Burnout, Motivation and Job Satisfaction"; QoL: Quality of life; UM/JMH: University of Miami/Jackson Memo- rial Hospital; US: United States; USF: University of South Florida Morsani School of Medicine; USMG: United States medical graduate; USMLE: United States Medical Licensing Examination.}

\section{Acknowledgements}

The authors would like to acknowledge Ann Cata, Halcyon Quinn and James Miller for assistance with data entry.

\section{Authors' contributions}

JES participated in study design, data collection, statistical analysis and writing of the manuscript. AH participated in the study design, data collection and writing. YD participated in the study design, data collection and writing. ATP participated in the study design, statistical analysis and writing. LT participated in statistical analysis and writing, CP participated in the study design, data collection and writing, AP participated in the statistical analysis and writing. All authors read and approved the final manuscript.

\section{Authors' information}

JES is a professor in the Department of Medicine and Senior Associate Dean for Faculty Affairs and Graduate Medical Education at the University of Miami Miller School of Medicine in Miami, Florida. She is the former Designated Institutional Official at University of Miami/Jackson Health System.

HA is a professor in the Departments of Family Medicine, Medicine and Surgery at the University of Miami Miller School of Medicine in Miami, Florida.

YD is an associate professor in the Department of Medicine and the Associate Dean for Graduate Medical Education at the University of Miami Miller School of Medicine. She is the Designated Institutional Official for the University of Miami/Jackson Health System in Miami, Florida.

ATP is a resident at the Morehouse University School of Medicine Family Medicine Residency in Atlanta, Georgia.

LP is a professor in the Department of Medicine, and the Director of the Resident Scholarly Activity Program at the University of Miami Miller School of Medicine in Miami, Florida. 
CP is Chief, General Surgery, Nemours A.I. duPont Hospital for Children and Professor, Departments of Surgery, Pediatrics, and Medical Oncology, Sidney Kimmel Medical College, Thomas Jefferson University, Philadelphia, Pennsylvania. He is the former Designated Institutional Official, Morsani College of Medicine, University of South Florida, Tampa, Florida.

AP is a professor in the Department of Public Health Sciences, and Assistant Director of the Educational Development Office at the University of Miami Miller School of Medicine in Miami, Florida.

\section{Funding}

There was no external funding for this study.

\section{Availability of data and materials}

The datasets generated and/or analyzed during the current study are not publicly available due to requirements of the institutional review board, but are available from the corresponding author on reasonable request.

\section{Declarations}

\section{Ethics approval and consent to participate}

The University of Miami Miller School of Medicine Institutional Review Board approved this study. All participants gave written consent to participate in this study.

\section{Consent for publication}

Not applicable.

\section{Competing interests}

The authors have no competing interests.

\section{Author details}

${ }^{1}$ Department of Medicine, University of Miami Leonard M. Miller School of Medicine, 1600 NW 10th Avenue, Suite 1124, Miami, Florida 33136, USA. ${ }^{2}$ Department of Community and Family Medicine, University of Miami Leonard M. Miller School of Medicine, Miami, Florida, USA. ${ }^{3}$ Graduate Medical Education, Jackson Memorial Hospital/Jackson Health System, Miami, Florida, USA. ${ }^{4}$ Department of Family Medicine, Morehouse University School of Medicine, Atlanta, Georgia, USA. ${ }^{5}$ Nemours A.I. duPont Hospital for Children, Wilmington, Delaware, USA. ${ }^{6}$ Department of Surgery, Sidney Kimmel Medical College, Thomas Jefferson University, Philadelphia, Pennsylvania, USA. ${ }^{7}$ Department of Public Health Sciences, Leonard M. Miller School of Medicine, Miami, Florida, USA.

Received: 25 July 2020 Accepted: 20 January 2022

Published online: 29 January 2022

\section{References}

1. Maslach C, Leiter M. Understanding the burnout experience: recent research and its implications for psychiatry. World Psychiatry. 2016;15:103-11.

2. Shanafelt TD, Hasan O, Dyrbye LN, et al. Changes in burnout and satisfaction with work-life balance in physicians and the general US population, 2011-2014. Mayo Clin Proc. 2015;90(12):1600-13.

3. Dyrbye LN, West CP, Satele D, et al. Burnout among U.S. medical students, residents, and early career physicians relative to the general U.S. population. Acad Med. 2014;89(3):443-51.

4. Dyrbye LN, Massie FS, Eacker A, et al. Relationship between burnout and professional conduct and attitudes among US medical students. JAMA. 2010;304(11):1173-80.

5. Martini S, Arfken CL, Churchill A, Balon R. Burnout comparison among residents in different medical specialties. Acad Psychiatry. 2004;28(3):240-2.

6. Prins JT, Gazendam-Donofrio SM, Tubben BJ, Van Der Heijden FMMA, Wiel VD, Hoekstra-Weebers JEHM. Burnout in medical residents: a review. Med Educ. 2007;41(8):788-800.

7. Goldberg R, Boss RW, Chan L, et al. Burnout and its correlates in emergency physicians: four years' experience with a wellness booth. Acad Emerg Med. 1996;3(12):1156-64.
8. Rabatin J, Williams E, Baier Manwell L, Schwartz MD, Brown RL, Linzer M. Predictors and outcomes of burnout in primary care physicians. J Prim Care Community Health. 2016;7(1):41-3.

9. Shanafelt TD, Balch CM, Dyrbye L, et al. Special report: suicidal ideation among American surgeons. Arch Surg. 2011;146(1):54-62.

10. Shanafelt TD, Balch CM, Bechamps G, et al. Burnout and medical errors among american surgeons. Ann Surg. 2010;251(6):995-1000.

11. Wallace JE, Lemaire JB, Ghali WA. Physician wellness: a missing quality indicator. Lancet. 2009;374(9702):1714-21.

12. Dewa C, Loong D, Bonato S, Thanh NX, Jacobs P. How does burnout affect physician productivity? A systematic literature review. BMC Health Serv Res. 2014;14(1):325

13. Smeds MR, Janko MR, Allen S, et al. Burnout and its relationship with perceived stress, self-efficacy, depression, social support, and programmatic factors in general surgery residents. Am J Surg. 2020;219(6):907-12. https://doi.org/10.1016/j.amjsurg.2019.07.004.

14. Sargent MC, Sotile W, Sotile MO, Rubash H, Barrack RL. Stress and coping among orthopaedic surgery residents and faculty. J Bone Joint Surg Amer. 2004;86-A(7):1579-86.

15. Swami MK, Mathur DM, Pushp BK. Emotional intelligence, perceived stress and burnout among resident doctors: an assessment of the relationship. Natl Med J India. 2013;26(4):210-3.

16. Lebares CC, Guvva EV, Ascher NL, O'Sullivan PS, Harris HW, Epel ES. Burnout and stress among US surgery residents: psychological distress and resilience. J Am Coll Surg. 2018;226(1):80-90.

17. Shapiro J, Astin J, Shapiro SL, Robitshek D, Shapiro DH. Coping with loss of control in the practice of medicine. Fam Syst Health. 2011;29(1):15-28. https://doi.org/10.1037/a0022921.

18. Taylor DM, Pallant JF, Crook HD, Cameron PA. The psychological health of emergency physicians in Australasia. Emerg Med Australas. 2004;16(1):21-7. https://doi.org/10.1111/j.1742-6723.2004.00532.x.

19. Eckleberry-Hunt J, Lick D, Boura J, et al. An exploratory study of resident burnout and wellness. Acad Med. 2009;84(2):269-77.

20. Lebensohn P, Dodds S, Benn R, Brooks AJ, Birch M, Cook P, et al. Resident wellness behaviors: relationship to stress, depression, and burnout. Fam Med. 2013;45(8):541-9.

21. Shanafelt TD, Oreskovich MR, Dyrbye LN, et al. Avoiding burnout: the personal health habits and wellness practices of US surgeons. Ann Surg. 2012;255(4):625.

22. Doolittle BR, Windish DM. Correlation of burnout syndrome with specific coping strategies, behaviors, and spiritual attitudes among interns at Yale University, New Haven, USA. J Educ Eval Health Prof. 2015;12:41.

23. Estupiñan B, Kibble J. The relationship between spirituality and burnout in the lives of medical students. Med Sci Educ. 2018;28:37-44. https://doi. org/10.1007/s40670-017-0490-5.

24. Wachholtz A, Rogoff M. The relationship between spirituality and burnout in medical students. J Contemp Med Educ. 2013;1(2):83-91.

25. Ray C, Wyatt TR. Religion and spirituality as a cultural asset in medical students. J Relig Health. 2018;57(3):1062.

26. West CP, Shanafelt TD, Kolars JC. Quality of life, burnout, educational debt, and medical knowledge among internal medicine residents. JAMA. 2011;306(9):952-60.

27. Weidner AKH, Phillips RL, Fang B, Peterson LE. Burnout and scope of practice in new family physicians. Ann Fam Med. 2018;16(3):200-5.

28. Gozu A, Kern DE, Wright SM. Similarities and differences between international medical graduates and U.S. medical graduates at six Maryland community-based internal medicine residency training programs. Acad Med. 2009;84(3):385-90.

29. Baldwin DC, Dougherty SR. How residents say they learn: a national, multi-specialty survey of first- and second-year residents. JGME. 2016;8(4):631-9. https://doi.org/10.4300/JGME-D-16-00182.1.

30. Kristensen TS, Borritz M, Villadsen E, Christensen KB. The Copenhagen burnout inventory: a new tool for the assessment of burnout. Work Stress. 2005:19(3):192-207.

31. Thrush CR, Guise JB, Gathright MM, et al. A one-year institutional view of resident physician burnout. Acad Psychiatry. 2019;43:361-8. https://doi. org/10.1007/s40596-019-01043-9.

32. Papaefstathiou E, Tsounis A, Papaefstathiou E, Malliarou M, Sergentanis T, Sarafis P. Impact of hospital educational environment and occupational stress on burnout among Greek medical residents. BMC Res Notes. 2019;12(1):281. https://doi.org/10.1186/s13104-019-4326-9. 
33. Pearlin LI, Schooler C. The structure of coping. J Health Soc Behav. 1978;19(1):2-21.

34. Pearlin LI, Lieberman MA, Menaghan EG, Mullan JT. The stress process. J Health Soc Behav. 1981;22(4):337-56.

35. Cohen S, Williamson G. Perceived stress in a probability sample of the United States. In: Spacapan S, Oskamp S, editors. The social psychology of health: Claremont symposium on applied social psychology. Newbury Park: Sage; 1988. p. 31-67.

36. Kroenke K, Spitzer RL, Williams JBW. The patient health questionnaire-2: validity of a two-item depression screener. Med Care. 2003;41(11):1284-92.

37. Arroll B, Goodyear-Smith F, Crengle S, et al. Validation of PHQ-2 and PHQ-9 to screen for major depression in the primary care population. Ann Fam Med. 2010;8(4):348-53.

38. King M, Speck P, Thomas A. The Royal Free interview for spiritual and religious beliefs: development and validation of a self-report version. Psychol Med. 2001;31:1015.

39. Michalos AC. Quality of life, two-variable theory. In: Michalos AC, editor. Encyclopedia of quality of life and well-being research. Dordrecht: Springer; 2014. https://doi.org/10.1007/978-94-007-0753-5_3930.

40. Allespach H, Diaz Y, Burg MA, St Onge JE. Daily self-care and cognitive restructuring: a potentially potent prescription for physician wellness. Cogent Medicine. 2019. https://doi.org/10.1080/2331205X.2019.1704151.

41. Afzal Kl, Khan FM, Mulla Z, Akins R, Ledger E, Giordano FL. Primary language and cultural background as factors in resident burnout in medical specialties: a study in a bilingual US city. South Med J. 2010;103(7):607-15.

42. Salmoirago-Blotcher E, Fitchett G, Leung K, et al. An exploration of the role of religion/spirituality in the promotion of physicians' wellbeing in emergency medicine. Prev Med Rep. 2016;3:189-95. https://doi.org/10. 1016/j.pmedr.2016.01.009.

43. Bianchi R, Schonfeld IS, Laurent E. Burnout-depression overlap: a review. Clin Psychol Rev. 2015;36:28-41.

44. Brazeau CM, Shanafelt T, Durning SJ, et al. Distress among matriculating medical students relative to the general population. Acad Med. 2014;89(11):1520-5.

45. Zavlin D, Jubbal KT, Noé JG, Gansbacher B. A comparison of medical education in Germany and the United States: from applying to medical school to the beginnings of residency. GMS German. Med Sci. 2017;15:Doc15 https://digitalcommons.wustl.edu/open_access_pubs/ 6458

46. Chen DR, Priest KC, Batten JN, Fragoso LE, Reinfield BI, Laitman BM. Student perspectives on the "step 1 climate" in preclinical medical education. Acad Med. 2019;94(3):302-4.

47. Change to pass/fail score reporting for Step 1. United States Medical Licensing Examination InCUS: Invitational Conference on USMLE Scoring. USMLE website. Accessed 31 Oct 2020. https://www.usmle.org/incus/

\section{Publisher's Note}

Springer Nature remains neutral with regard to jurisdictional claims in published maps and institutional affiliations.

Ready to submit your research? Choose BMC and benefit from:

- fast, convenient online submission

- thorough peer review by experienced researchers in your field

- rapid publication on acceptance

- support for research data, including large and complex data types

- gold Open Access which fosters wider collaboration and increased citations

- maximum visibility for your research: over 100M website views per year

At BMC, research is always in progress.

Learn more biomedcentral.com/submissions 